American Journal of Applied Sciences 5 (11): 1424-1428, 2008

ISSN 1546-9239

(C) 2008 Science Publications

\title{
Performance Comparison of Three-Phase Shunt Active Power Filter Algorithms
}

\author{
${ }^{1}$ Moleykutty George and ${ }^{2}$ Kartik Prasad Basu \\ ${ }^{1}$ Faculty of Engineering and Technology, Multimedia University,75450 Melaka, Malaysia \\ ${ }^{2}$ Faculty of Engineering, Multimedia University, 63100 Cyberjaya, Malaysia
}

\begin{abstract}
The usage of parallel converters is ever increasing. However, the voltage and current harmonics, zero-sequence and negative- sequence components of voltage and current and reactive power present in parallel converters give an alarming signal to power system and power electronic engineers. This research discusses performance of three-phase shunt active power filter (APF) system using three different control techniques namely synchronous detection algorithm (SDM), instantaneous active and reactive (p-q) theory and instantaneous direct and quadrature (d-q) current method for the control of zero and negative sequence components, reactive power and harmonics. The novelty of this research lies in the successful application of SDM based APF and (d-q) current method APF for the control of reactive power, harmonics and negative and zero sequence currents resulted by the use of parallel three-phase converters. MATLAB 6.1 toolbox is used to model the systems.
\end{abstract}

Key words: parallel converters, zero-sequence, negative sequence, SDM, p-q theory, d-q method

\section{INTRODUCTION}

The usage of parallel converters is increasing due to high reliability, high power, distributed power, high performance and enabling technology for emerging applications ${ }^{[1]}$. However the presence of zero-sequence and negative- sequence components of voltage and current harmonics and reactive power present in parallel converters introduces many adverse effects. The presence of negative-sequence and/ zero-sequence components introduces asymmetry and is an indication of abnormal condition in which these components are found.

APF systems have been successfully introduced for the control of zero-sequence and negative-sequence components in unbalanced systems ${ }^{[2-4]}$ and control of zero-sequence components in parallel converters ${ }^{[5]}$. A detailed discussion on modeling of parallel converters and control of circulating zero-sequence currents and reactive power circulation has been discussed in ${ }^{[1]}$.

This research discusses the performances of APF systems using SDM, p-q theory and (d-q) current method for the control of zero and negative sequence components of current, reactive power and current harmonics. The novelty of this research lies in the successful application of SDM based APF and (d-q) current method APF for the control of reactive power, harmonics and negative and zero sequence currents resulted by the use of parallel three-phase converters. The control strategies of APF system are detailed in the second part of this research. Simulation results in the third part demonstrate the effectiveness of SDM and (dq)current method for the control of APF system to achieve balanced current sinusoids in phase with the supply voltages.

\section{CONTROL OF APF SYSTEM}

Principle of operation: Basically an APF system ${ }^{[6]}$ is used for current compensation. The compensation currents are generated by properly controlling the voltage source inverter (VSI) in the current control mode. It has been observed that for the successful operation of APF system the capacitor voltage of the inverter system should be 1.5 times the maximum lineto-line voltage ${ }^{[6]}$. A booster inductor could be used to convert the VSI in the current control mode. In this research VSI is assumed to be instantaneous and infinitely fast to track the compensation currents, hence it is modeled as a current amplifier with unity gain and the simulink model of the inverter sub system used is shown in Fig. $1^{[7]}$. Three different control algorithms namely SDM, p-q theory and d-q current method are discussed to generate the compensation currents.

Corresponding Author: Moleykutty George, Faulty of Engineering and Technology, Melaka Campus, Multimedia University, 75450, Melaka, Malaysia Tel: +606 2523286 Fax: +606-231 6552 


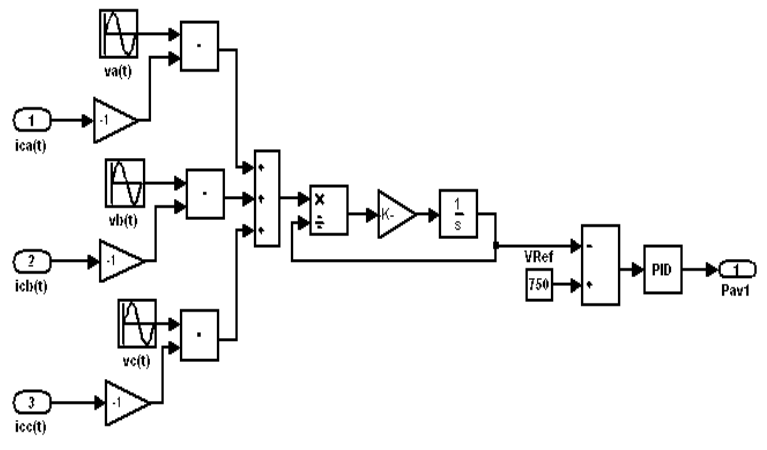

Fig. 1: Inverter sub-system

Control of APF system using SDM: In this algorithm, the three-phase source currents are assumed to be balanced after compensation. The real power $\mathrm{p}(\mathrm{t})$ consumed by the load could be calculated from the instantaneous voltages and load currents as:

$$
p(t)=\left[v_{s a}(t) v_{s b}(t) v_{s c}(t)\right]\left[\begin{array}{l}
i_{l a}(t) \\
i_{b b}(t) \\
i_{l c}(t)
\end{array}\right]
$$

where, $v_{\mathrm{sa}}(t), v_{\mathrm{sb}}(t), v_{\mathrm{sc}}(t)$ are the instantaneous values of supply voltages and $\mathrm{i}_{\mathrm{la}}(\mathrm{t}), \quad \mathrm{i}_{\mathrm{lb}}(\mathrm{t}), \quad \mathrm{i}_{\mathrm{lc}}(\mathrm{t})$ are the instantaneous values of load currents. The average value $P_{d c}$ is determined by applying $p(t)$ to a low pass filter. The real power is then split into the three phases as follows:

$$
\begin{aligned}
& P_{\mathrm{a}}=\frac{\mathrm{P}_{\mathrm{dc}} \times \mathrm{V}_{\mathrm{sma}}}{\mathrm{V}_{\mathrm{sma}}+\mathrm{V}_{\mathrm{smb}}+\mathrm{V}_{\mathrm{smc}}} \\
& \mathrm{P}_{\mathrm{b}}=\frac{\mathrm{P}_{\mathrm{dc}} \times \mathrm{V}_{\mathrm{smb}}}{\mathrm{V}_{\mathrm{sma}}+\mathrm{V}_{\mathrm{smb}}+\mathrm{V}_{\mathrm{smc}}} \\
& \mathrm{P}_{\mathrm{c}}=\frac{\mathrm{P}_{\mathrm{dc}} \times \mathrm{V}_{\mathrm{smc}}}{\mathrm{V}_{\mathrm{sma}}+\mathrm{V}_{\mathrm{smb}}+\mathrm{V}_{\mathrm{smc}}}
\end{aligned}
$$

Thus for purely sinusoidal balanced supply voltages:

$$
\mathrm{P}_{\mathrm{a}}=\mathrm{P}_{\mathrm{b}}=\mathrm{P}_{\mathrm{c}}=\frac{\mathrm{P}_{\mathrm{dc}}}{3}
$$

where,

$$
\begin{gathered}
\mathrm{P}_{\mathrm{a}}=\mathrm{V}_{\mathrm{sa}} \times \mathrm{I}_{\mathrm{sa}}=\frac{\mathrm{V}_{\text {sma }}}{\sqrt{2}} \times \frac{\mathrm{I}_{\text {sma }}}{\sqrt{2}}=\frac{\mathrm{V}_{\text {sma }} \times \mathrm{I}_{\text {sma }}}{2} \\
\therefore \mathrm{I}_{\text {sma }}=\frac{2 \times \mathrm{P}_{\mathrm{a}}}{\mathrm{V}_{\text {sma }}}
\end{gathered}
$$

and the unit amplitude wave form in synchronism with the supply voltage is given by:

$$
\frac{\mathrm{v}_{\mathrm{sa}}(\mathrm{t})}{\mathrm{V}_{\mathrm{sma}}}
$$

Thus the reference source current:

$$
\mathrm{i}_{\mathrm{sa}}(\mathrm{t})=\frac{2 \times \mathrm{v}_{\mathrm{sa}}(\mathrm{t}) \times \mathrm{P}_{\mathrm{a}}}{\mathrm{V}_{\mathrm{sma}}{ }^{2}}
$$

Similarly

$$
\begin{aligned}
& \mathrm{i}_{\mathrm{sb}}(\mathrm{t})=\frac{2 \times \mathrm{v}_{\mathrm{sb}}(\mathrm{t}) \times \mathrm{P}_{\mathrm{b}}}{\mathrm{V}_{\mathrm{smb}}{ }^{2}} \\
& \mathrm{i}_{\mathrm{sc}}(\mathrm{t})=\frac{2 \times \mathrm{v}_{\mathrm{sc}}(\mathrm{t}) \times \mathrm{P}_{\mathrm{c}}}{\mathrm{V}_{\mathrm{smc}}{ }^{2}}
\end{aligned}
$$

where, $\mathrm{V}_{\mathrm{sma}}, \mathrm{V}_{\mathrm{smb}}, \mathrm{C}_{\mathrm{smc}}$ are the amplitudes of the supply voltages. The compensation currents are then calculated using Eq. 8a-8c:

$$
\begin{aligned}
& \mathrm{i}_{c a}(t)=i_{s a}(t)-i_{l a}(t) \\
& i_{c b}(t)=i_{s b}(t)-i_{l b}(t) \\
& i_{c c}(t)=i_{s c}(t)-i_{l c}(t)
\end{aligned}
$$

Control of APF system using p-q theory: The p-q theory proposed by $\mathrm{Akagi}^{[8]}$ to determine the compensation current to be injected by the APF system for harmonic elimination and reactive power uses Park's transformation from three-phases $(a, b, c)$ to two phases $(\alpha$ and $\beta)$. The three phase supply voltages and load currents could be transformed into the $\alpha-\beta$. orthogonal coordinates as follows:

$$
\begin{aligned}
& {\left[\begin{array}{l}
\mathrm{v}_{\mathrm{s \alpha}}(\mathrm{t}) \\
\mathrm{v}_{\mathrm{sp}}(\mathrm{t})
\end{array}\right]=\sqrt{\frac{2}{3}}\left[\begin{array}{l}
1-1 / 2-1 / 2 \\
0 \sqrt{3} / 2-\sqrt{3} / 2
\end{array}\right]\left[\begin{array}{l}
\mathrm{v}_{\mathrm{sa}}(\mathrm{t}) \\
\mathrm{v}_{\mathrm{sb}}(\mathrm{t}) \\
\mathrm{v}_{\mathrm{sc}}(\mathrm{t})
\end{array}\right]} \\
& {\left[\begin{array}{l}
\mathrm{i}_{1 \alpha}(\mathrm{t}) \\
\mathrm{i}_{1 \beta}(\mathrm{t})
\end{array}\right]=\sqrt{\frac{2}{3}}\left[\begin{array}{lll}
1 & -1 / 2 & -1 / 2 \\
0 & \sqrt{3} / 2 & -\sqrt{3} / 2
\end{array}\right]\left[\begin{array}{l}
\mathrm{i}_{\mathrm{la}}(\mathrm{t}) \\
\mathrm{i}_{\mathrm{lb}}(\mathrm{t}) \\
\mathrm{i}_{\mathrm{lc}}(\mathrm{t})
\end{array}\right]}
\end{aligned}
$$

According to $\mathrm{p}-\mathrm{q}$ theory, determination of instantaneous real power $\mathrm{p}_{1}(\mathrm{t})$ and imaginary power $\mathrm{q}_{\mathrm{l}}(\mathrm{t})$ is given by the expression: 
Am. J. Applied Sci., 5 (11): 1424-1428, 2008

$$
\left[\begin{array}{l}
p_{1}(t) \\
q_{1}(t)
\end{array}\right]=\left[\begin{array}{ll}
v_{s \alpha}(t) & v_{s \beta}(t) \\
-v_{s \beta}(t) & v_{s \alpha}(t)
\end{array}\right]\left[\begin{array}{l}
i_{1 \alpha}(t) \\
i_{1 \beta}(t)
\end{array}\right]
$$

where, $p_{1}(t)$ and $q_{1}(t)$ contain dc and ac terms and can be written as:

$$
\begin{aligned}
& \mathrm{p}_{1}(\mathrm{t})=\overline{\mathrm{p}}+\tilde{\mathrm{p}} \\
& \mathrm{q}_{1}(\mathrm{t})=\overline{\mathrm{q}}+\tilde{\mathrm{q}}
\end{aligned}
$$

To achieve unity power factor and harmonic elimination, the ac term $\tilde{p}$ and the imaginary power $\mathrm{q}_{1}(\mathrm{t})$ have to be eliminated. The compensation power $\tilde{p}$ could be obtained by filtering out the ac components from $\mathrm{p}_{1}(\mathrm{t})$. Thus:

$$
\mathrm{p}_{\mathrm{c}}^{*}(\mathrm{t})=\tilde{\mathrm{p}}
$$

and

$$
\mathrm{q}_{\mathrm{c}}^{*}(\mathrm{t})=\mathrm{q}_{1}(\mathrm{t})
$$

The reference compensation current in the $\alpha-\beta$ plane is given by the expression:

$$
\left[\begin{array}{l}
i^{*}{ }_{c \alpha}(t) \\
i^{*}{ }_{c \beta}(t)
\end{array}\right]=\left[\begin{array}{cc}
v_{s \alpha}(t) & v_{s \beta}(t) \\
-v_{s \beta}(t) & v_{s \alpha}(t)
\end{array}\right]^{-1}\left[\begin{array}{l}
p_{c}^{*}(t) \\
q_{c}^{*}(t)
\end{array}\right]
$$

and the reference compensation currents for phase a, phase b and phase c could be evaluated using Park's backward transformation and given in matrix form as follows:

$$
\left[\begin{array}{l}
\mathrm{i}^{*}{ }^{*}(t) \\
\mathrm{i}^{*}{ }^{*}(\mathrm{t}) \\
\mathrm{i}^{*}{ }^{*}{ }_{c c}(t)
\end{array}\right]=\sqrt{\frac{2}{3}}\left[\begin{array}{ll}
1 & 0 \\
-1 / 2 & \sqrt{3} / 2 \\
-1 / 2 & -\sqrt{3} / 2
\end{array}\right]\left[\begin{array}{l}
\mathrm{i}^{*}{ }^{*}(\mathrm{t}) \\
\mathrm{i}^{*}{ }_{\mathrm{c} \beta}(\mathrm{t})
\end{array}\right]
$$

Control of APF system using d-q current method: Figure 2 shows the block diagram of control circuit of an APF system using d-q current method. In this method positive sequence component of the first harmonic component of load current has been treated as the d-axis component of the reference source current, where as the q-axis component of reference source current is zero in an ideal balanced three-phase system. Now the reference source currents in the a, b, c plane could be obtained by the use of Park's transformation from stationary axes d, q to a, b, c frame as follows: $\left[\begin{array}{l}i^{*}{ }_{s a}(t) \\ i^{*}{ }_{s b}(t) \\ i^{*}{ }^{*}(t)\end{array}\right]=\left[\begin{array}{ll}\cos \theta & -\sin \theta \\ \cos \left(\theta-120^{\circ}\right) & -\sin \left(\theta-120^{\circ}\right) \\ \cos \left(\theta-240^{\circ}\right) & -\sin \left(\theta-240^{\circ}\right)\end{array}\right]\left[\begin{array}{l}i^{*}{ }_{s d}^{*}(t) \\ i^{*}(t)\end{array}\right]$

And the compensation currents are then calculated using the same Eq. 8a-8c used in SDM.

\section{RESULTS AND DISCUSSION}

APF systems based on SDM, p-q theory, d-q theory has been successfully modeled and tested using MATLAB 6.1 toolbox for the control of zero sequence and negative sequence components, harmonic components and reactive power resulted by the use of parallel three-phase converters. The effectiveness of the system has been successfully tested for different firing angles with two parallel converters. The performance of the developed systems is illustrated for $\alpha_{1}=0^{\circ}$ and $\alpha_{2}=90^{\circ}$ as shown in Fig. 3-13. One may note that unbalanced parallel converters introduce reactive power, harmonics, negative and zero sequence components of fundamental and harmonic components. It has been observed that APF based on p-q theory fails to completely eliminate negative and zero sequence components. The performance of the system using d-q current method is comparable with that of SDM and SDM shows supremacy in achieving three balanced current sinusoids in phase with the supply voltages.

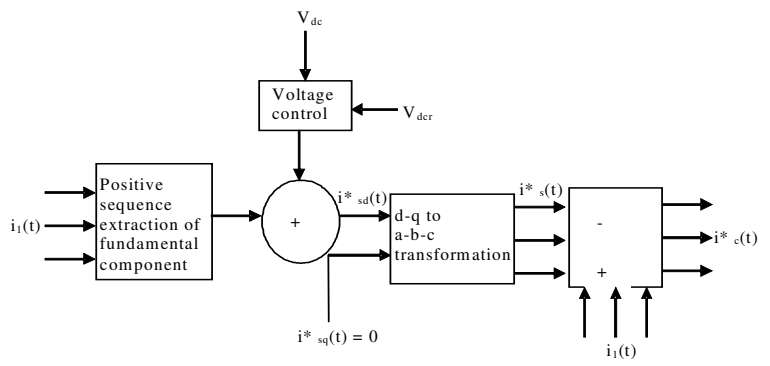

Fig. 2: Control circuit of APF system d-q using current method

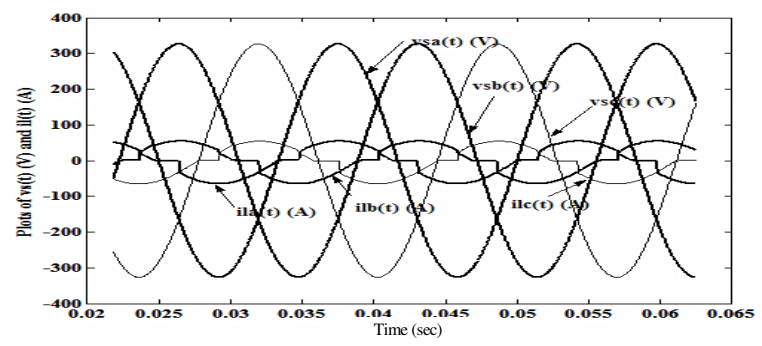

Fig. 3: Plots of source voltages and source currents 


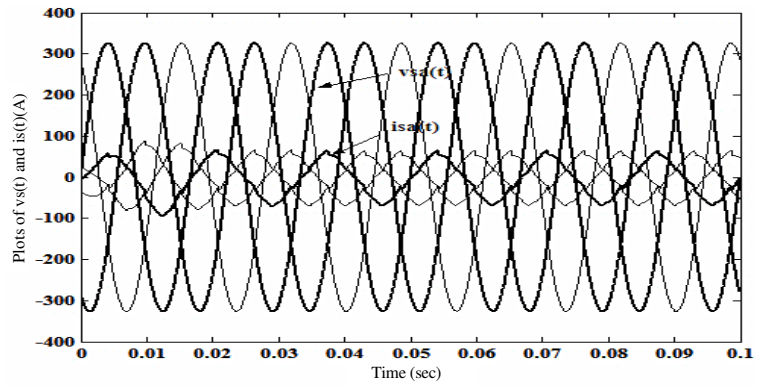

Fig. 4: Plots of Source voltages and source currents using p-q theory

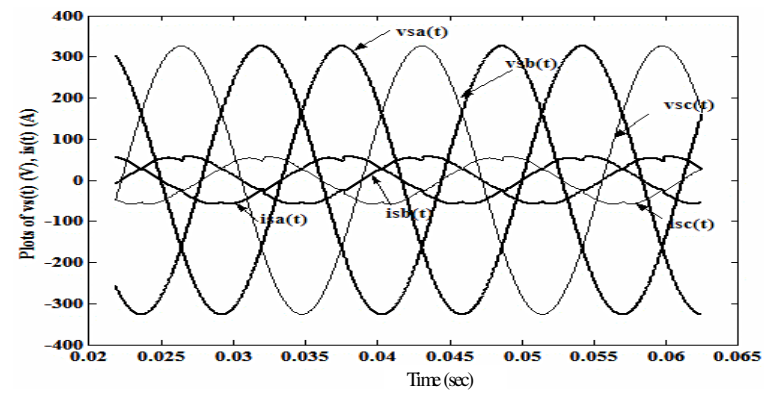

Fig. 5: Plots of Source voltages and source currents using p-q method

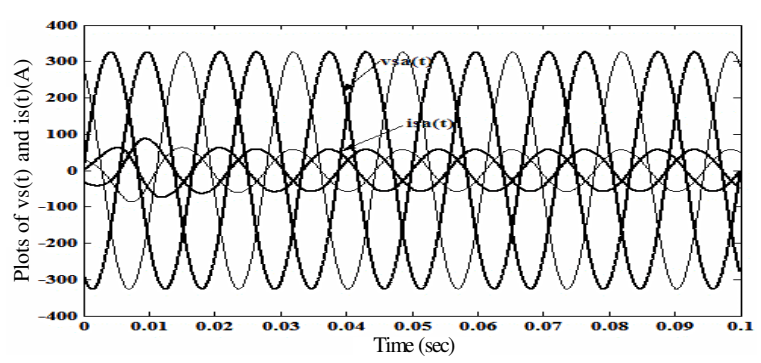

Fig. 6: Plots Source voltages and source currents using SDM

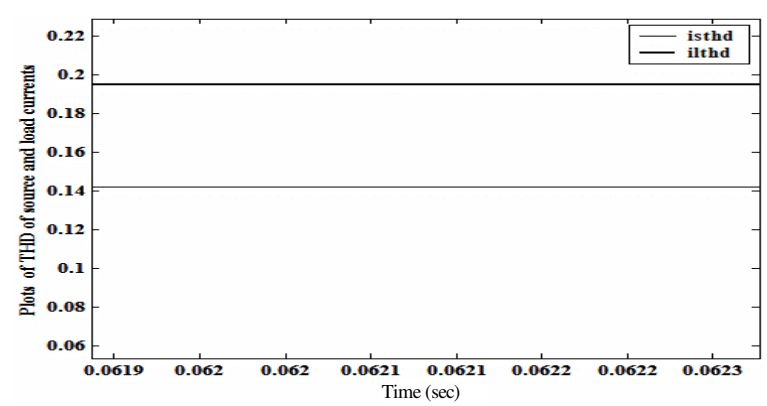

Fig. 7: THD's of load and source currents using p-q method

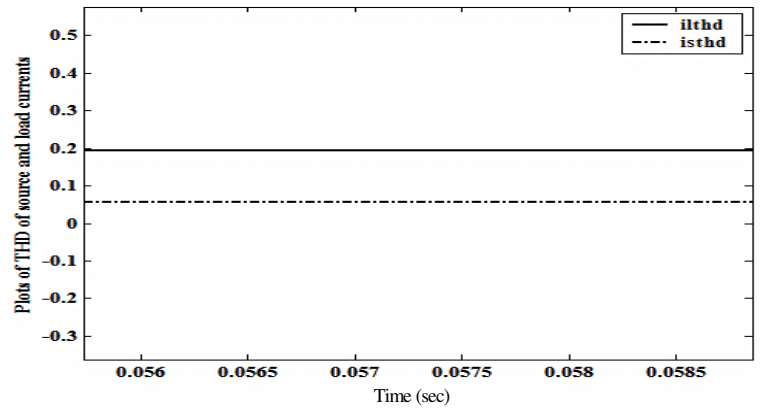

Fig. 8: THD's of load and source currents using d-q method

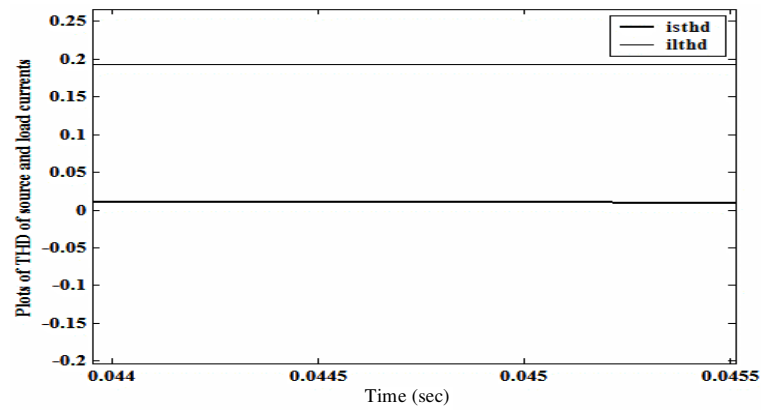

Fig. 9: THD's of load and source currents using SDM

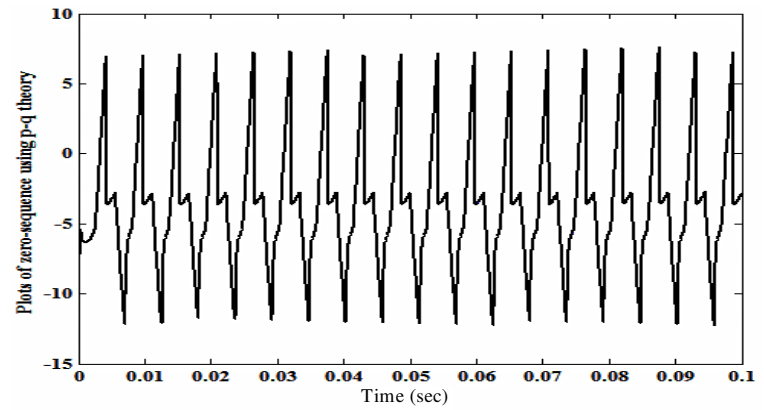

Fig. 10: Plot of zero-sequence current using p-q theory

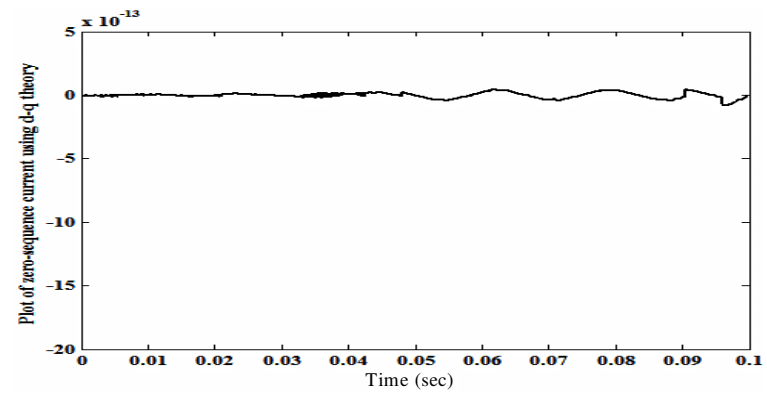

Fig. 11: Plot of zero-sequence current using d-q theory 


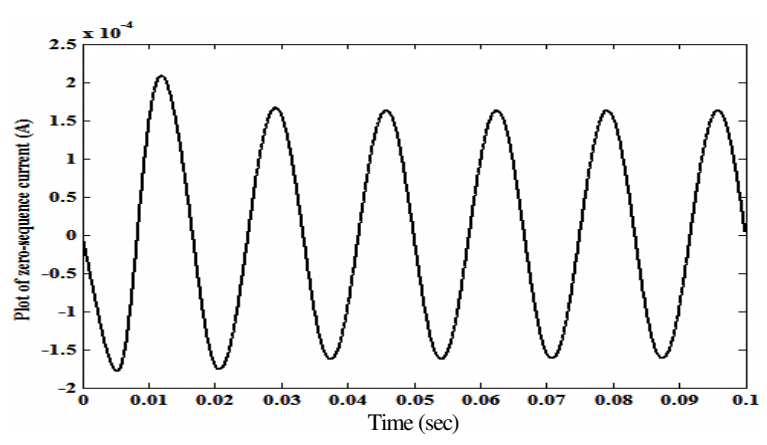

Fig. 12: Plot of zero sequence current using SDM method

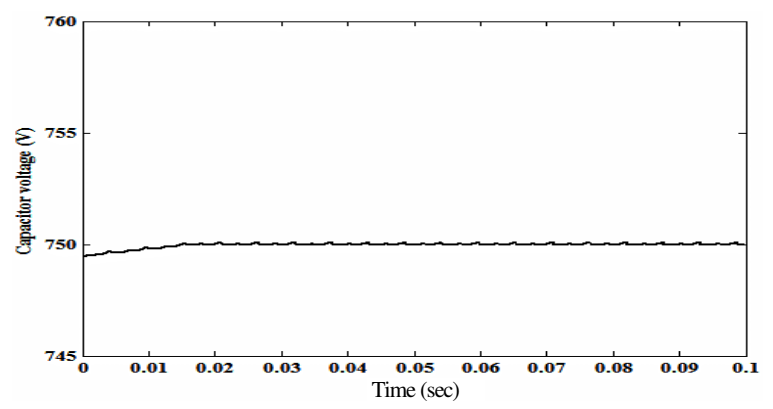

Fig. 13: Capacitor voltage obtained using

\section{CONCLUSION}

APF systems based on SDM, p-q theory, d-q current method have been successfully developed using MATLAB 6.1 toolbox. The novelty of this research lies in the successful application of SDM based APF and dq current method APF for the control of reactive power, harmonics and negative and zero sequence currents resulted by the use of parallel three-phase converters. It has been observed that APF system based on $p-q$ theory fails to achieve the desired target.

\section{ACKNOWLEDGMENT}

The authors are grateful to Alan Tan Wee Chiat, Dr. Abdulazeez S. Boujarwah, Christo George, K. S. Suresh Kumar, Prof. K Ramar and Dr. Saurabh Kumar Mukerji for valuable discussions.

\section{REFERENCES}

1. Zhilong, Y., 2000. Modeling and Control of Parallel Three-Phase PWM Converters: Theses Report, Virginia Polytechnic Institute and State University, http://scholar.lib.vt.edu/.

2. Bhavaraju, V.B. and P.N. Enjeti, 1993. Analysis and design of an active power filter for balancing unbalanced loads: IEEE Trans. Power Electron., 8 (4): 640-647.

3. Bhavaraju, V.B. and P.N. Enjeti, 1996. An active line conditioner to balance voltages in a threephase system: IEEE Trans. Ind. Appl., 32 (2): 287-292.

4. Enjeti, P.N., W. Shireen, P. Packebush and I.J. Pitel, 1994. Analysis and design of a new active power filter to cancel neutral current harmonics in three-phase four-wire electric distribution systems. IEEE Trans. Ind. Appl., 30 (6): 1565-1572.

5. George, M. and C.L. Seen, 2004. Modeling and control of zero-sequence current of parallel threephase converters using Matlab/power system blockset. IEEE Power Systems Conf. and Exp. 2004, 3: 1440-1443.

6. Moleykutty George, 2004. Modeling and simulation of a current controlled three-phase shunt active power filter using MATLAB/PSB. AIUB. J. Sci. Eng., 3 (1): 11-18.

7. Suresh Kumar K. S., 2004, Three-phase shunt active power filters, part III-Simulation of control systems: Selected topics in power quality and custom power, pp.3.

8. Akagi, H., 1994. Trends in active power line conditioners. IEEE Tran. Power Electron., 9 (3): 263-268. 